\title{
PRESCHOOL PRACTITIONERS' AND IMMIGRANT PARENTS'BELIEFS ABOUT ACADEMICS AND PLAY IN THE EARLY CHILDHOOD EDUCATIONAL CURRICULUM IN FIVE COUNTRIES
}

\author{
JOSEPH TOBIN, FIKRIYE KURBAN \\ Arizona State University
}

\begin{abstract}
Children Crossing Borders is a comparative study of how early childhood education and care programs in England, France, Germany, Italy, and the US are approaching the task of working with children of recent immigrants and of areas of agreement and disagreement in beliefs about what should happen in preschool of recent immigrant parents of young children and their children's teachers. The method used in the study is a version of video-cued ethnographic interviewing, in which preschool parents and practitioners were shown 20-minute videos of days in preschools in their own and other countries and asked for their reactions and evaluations. This paper focuses on how immigrant parents and preschool practitioners talk about the ideal balance of academic preparation and play in the curriculum. A key finding is that immigrant parents tend to favor greater emphasis on academic instruction than do their children's teachers, except in France, where teachers as well as parents see preschool as a place for academics rather than for play. Our analysis suggests that reasons for immigrant parents' preference for a greater academic emphasis include past experience with education in their host country; pragmatic concerns about their children's vulnerability to failing in school; and ideological beliefs about curriculum and pedagogy that are tied to a larger social conservatism as well as to social class.
\end{abstract}

Key words: early childhood education, immigrant families, ethnography, comparative approach

\section{Introduction}

Immigration is a challenging social and political issue for the United States and the countries of the European Union. It is a key political issue that connects domestic to international policies, that is closely linked with urban poverty and related social problems, and that reflects core concerns about what it means to be a nation, a people, and a union. The treatment of immigrants has become even more salient in the post-911, post-7/7, post-market crash climate of heightened concerns about national security, high rates of employment, and rising xenophobia. 
And immigration is a key issue for education as well, beginning with the education of young immigrant children.

A significant and growing percentage of the children enrolled in early childhood education and care (ECEC) programs in the United States and many countries in Europe are children of recent immigrants. For most young (3-5 years old) children of parents who have come from other countries and cultures, ECEC settings are the first context in which they come face to face with differences between the culture of home and the public culture of their new country. For parents who have recently immigrated to a new country, enrolling their child in an early childhood program is the paradigmatic moment where cultural values of their home and adopted culture come into contact and, often, conflict. For countries with high rates of immigration, ECEC programs are key sites for enacting national goals for social inclusion and the creation of new citizens. In the contemporary world preschools are the single most salient sites where the immigrant's culture of home meets the culture of the host society. As such, preschools that serve immigrant children and their families are crucibles for the creation of new citizens, new communities, and hybrid social and cultural forms.

And yet the field of early childhood education has conducted too little research on the experience of immigrant children and their families. The majority of the research that has been done in this area focuses on language issues, with much less attention to cultural issues. There has been very little research that focuses on the perspectives of immigrant parents.

With these concerns in mind, an interdisciplinary group of scholars from the US and Europe began meeting in 2002 to create what eventually became the fivecountry, comparative educational study we call "Children Crossing Borders." The research team includes specialists in early childhood education, child development, linguistics, and anthropology. The countries in this study are England, France, Germany, Italy, and the US. We eventually were successful in receiving major funding for the international research from the Bernard van Leer Foundation. The two authors of this paper coordinated the international research effort.

The research questions that guided this study are:

1. What do immigrant parents want for their children in ECEC programs?

2. How are the perspectives of immigrant parents like and unalike the perspectives of their children's preschool teachers and of non-immigrant parents?

3. What are the implications of our research findings for practice and policy for serving immigrant children and their families in ECEC programs?

The interviews we conducted with parents and teachers produced thousands of pages of transcripts of discussions on a wide range of issues including second language acquisition and home language retention; academic readiness; cultural and national identity; notions of childhood and child development; the role of the teacher; and parent-participation (Adair \& Tobin, 2009; Bove \& Mantovani, 2006; 
Brougere, Rayna, \& Guenif-Souilamas, 2008;.Guenif-Souilamas, 2008; Pascal \& Bertram, 2007; Tobin, Arzubiaga, \& Mantovani, 2007). In this paper we focus on just one of these issues: teachers' and immigrant parents' notions of the proper balance of academics and play in the early childhood curriculum.

\section{Method}

The method of this study is straightforward, and follows the approach Joseph Tobin used with David Wu and Dana Davidson in Preschools in Three Cultures: Japan, China, and the United States (1989) and with Hsueh Yeh and Mayumi Karasawa in the sequel, Preschool in Three Cultures Revisited (2009). As in those studies, in the Children Crossing Borders study we made videotapes of typical days in classrooms for four-year-olds in Early childhood education and care settings in each of the five countries, and then used these videotapes as tools to stimulate a multivocal, intercultural dialogue.

In this method, the videotapes function primarily not as data but rather as a cue or stimulus, like a set of interview questions in conventional social science research or an inkblot in a psychological study. The core assumption of the method is that the video material we shoot and edit is a stimulus that is simultaneously richer, better contextualized, and less abstract than a verbal question asked in an interview. For example, if we ask immigrant parents what sort of curricular approach they are looking for in preschool, the question is likely to be difficult to answer. But if we show them a videotape of a preschool in which children are seated behind desks in rows facing a teacher who is writing words on a blackboard, parents find it much easier to voice an opinion. Similarly, if we ask a practitioner in an ECEC setting to explain her approach to classroom management, the question is so abstract as to make a meaningful response difficult. Showing her a videotape made in her classroom in which a fight occurs and asking for her reactions and reflections works much better to elicit her beliefs.

The other key idea of the Preschool in Three Cultures method is the production of a multivocal conversation of parents, teachers, and directors in five countries all taking about the same set of tapes. As in a projective test, the differences in how people respond to our tapes reveal differences in their beliefs and worldviews. As we show a tape made in a classroom to the classroom practitioner, then to her supervisor and colleagues, and then to the parents of the children she cares for, and then to audiences of early childhood educators at other sites in her country and then in other countries, the effect is to create a virtual conversation among a diverse community of stakeholders.

By showing the same set of videotapes to parents and practitioners in multiple sites in each of the five nations in this study we were able to produce data that allows us to uncover similarities and differences in how each nation approaches the promises and challenges of bringing immigrants into the fabric of society and differences and similarities in the perspectives of parents (both immigrant and non-immigrant) and practitioners. 
The steps of the method are straightforward:

1. The research team in each country selected a site, a classroom for four-yearold children in a ECEC program serving a significant number of children of recent immigrants.

2. During a one-week visit, we shot a video of a more or less typical day.

3. Based on the initial feedback from the teacher, children, and parents, we edited the 10-12 hours of videotape from each site (5-6 hours per camera) down to approximately 2 hours and then down to 20 minutes. The logic of this winnowing process was to select a balance of shots that best reflect the program's approach to working children of immigrants and shots that we anticipated would function effectively as cues to stimulate informants to explicate their beliefs and philosophies.

4. We showed the edited video to the teacher(s) in whose classroom we filmed and made sure they were comfortable with everything in the video, and we then made additional edits, as needed.

5. We invited parents to watch and comment on the videotape made in their child's classroom.

6. We conducted focus-group sessions with parents and teachers in each country. The videotapes functioned as cues for these focus-group interviews, with groups of 4-10 parents or practitioners watching and discussing the tapes together.

We conducted these discussions with parents and practitioners in at least five sites in each country, sites, chosen to reflect regional, social class, and ideological variation. In these sessions we showed both the videotape made in a preschool in their country and videotapes from two of the other countries in the study. For example, French informants were shown the German and English tapes, while Italian informants were shown the French and US tapes. In each country, parent and teacher comments on what they found attractive and repugnant in the practices of other countries served to clarify and highlight their own beliefs and values.

This multivocal, multi-step method produced a great deal of data, in the form of thousands of pages of transcripts of the discussions we conducted with parents and practitioners. We conducted a total of about 150 focus groups across the five countries. From this larger set, we chose 75 ( 15 focus groups per country, ten with parents, five with practitioners) to transcribe, translate, and code. In some cases the transcripts were translated twice, as for example first from Turkish to German and then from German to English.

We used two parallel modes of analysis to make sense of these transcripts: content analysis (using a qualitative data analysis program, and the coding category framework we developed) and interpretive/textual analysis, which borrowed analytic techniques from structural anthropology, discourse analysis, and Bakhtinian literary analysis (Tobin, 2000).

We faced many problems of translation and definition of terms and concepts across borders and cultures. A challenge in any international study is arriving at shared definitions of key terms. This is partly a problem of translation (e.g. how 
to translate "école maternelle" into English) but more significantly a problem of contextualized meanings (the term "preschool" is used in both England and in the US, but the meanings are different). For the purposes of this study, we are using "early childhood education and care (ECEC) settings" to refer to a variety of institutions that serve three- to four-year-old children, including child centers, preschools, école maternelle, scuola dell'infanzia, reception, and kindergarten.

Even more difficult to define precisely than "early childhood education and care setting" is the term "immigrant." We use "immigrant" in the title of our project and in this paper in its generic, rather than legal sense, to refer to children whose families have recently migrated, whether permanently or temporarily, to the country where they are currently living.

Our analysis features several different levels of comparison, as our design allowed us to compare the perspectives of: parents and practitioners; immigrant and nonimmigrant parents; practitioners in five countries; and immigrant parents in five countries. We have data that allows us to make some conclusions about differences and similarities across these categories of informants, but we are mindful that this study is more contrastive than comparative in that although we endeavored to keep the method as consistent as possible, each context in which we conducted focus groups was different and for each of our categories of informants the task we asked of them was qualitatively unalike.

\section{Site Selection and the Problem of Typicality}

This use of this method inevitably raises questions of typicality: How can one early childhood setting per country be enough? How can we claim that one setting can be typical of a country, or that the day we videotaped is typical of other days in that setting? If we were using our videotapes as data, a videotape of one day in one program in one country would not be adequate. But we have used these videotapes not as data but as stimuli or cues to get a range of stakeholders in each country to talk about how early childhood programs should work with children of immigrants. What is important for our videos to work as stimuli is that they be typical enough so that viewers within each country will find what they show familiar and unexceptional. A viewer from an école maternelle in Lyon, for example, might find the videotape we made in an école maternelle in a suburb of Paris to be different in various ways from her program, but she should not be surprised that there could be such a program.

For site selection, we balanced comparability with typicality: the sites we selected for each country were as comparable as possible in terms of age of the children, the percentage of children who are immigrants; the heterogeneity of the setting, the socio-economic background of the families, and level of urbanization: each program serves four-year-olds, from struggling rather than middle-class families, in large cities. We selected a program in each country that serves children from a variety of cultural backgrounds and in which the percentage of immigrants is greater than $20 \%$. 
We were able to address the typicality of the day we videotaped by beginning our investigation by asking the practitioner of the classroom where we videotaped to tell us whether the tape we made shows a typical day and if not, in what ways it is atypical. By showing a tape made in one setting to audiences in five other settings in each country, we enlisted our informants in the task of helping us understand in what ways the site we have chosen is typical and in what ways it reflects regional, ideological, or programmatic variations within the country. For example, early childhood educators in (the former) East Germany and in Frankfurt did not hesitate to tell us how their approach differs from that of (West) Berlin.

\section{Academics and Play}

The question of the proper balance in the preschool curriculum between play and academic learning produced very different responses from country to country in our focus-group discussions. There was much discussion and debate about this issue in the US, with teachers declaring the value of a play-based curriculum and warning against the dangers of a "pushed-down" academic approach and immigrant parents (and many non-immigrant parents as well) wishing that their children's preschool would give more emphasis to the direct teaching of letters and numbers. In France, in contrast, teachers and parents were largely in agreement on this issue, with both teachers and immigrant parents supporting the école maternelle's emphasis on consigne (school instructions and rules) and school-like curriculum (Brougère, Guénif-Souilamas, \& Rayna, 2008). In England, Germany, and Italy, teachers were consistent in emphasizing the importance of a childcentered, play-based approach, and in rejecting a dichotomization of learning and play. Immigrant parents in these three European countries tended to want more emphasis on academics than did the teachers, but in their focus-group discussions they expressed this wish with somewhat less fervor and less often than did their counterparts in the US.

There is a research literature that suggests that parents who immigrate from more traditional societies, who are religious, and/or who are from working class urban or agrarian backgrounds (all of which are true for the majority of the immigrants in our study), tend to hold more conservative views on education than do contemporary progressive practitioners (Delpit, 1996; Valdes, 1996; Vandenbroeck, Roets, \&Snoeck, 2009; Tobin, Hsueh, \& Karasawa, 2009). This dynamic is true not only in the domain of education, but in other domains as well. This dynamic lies at the core of many of the tensions about the "Islamization of Europe", a fear voiced increasingly often in Europe that Islamic immigrants bring with them beliefs that are antithetical to the liberal, progressive, democratic, modern beliefs Europeans believe distinguish themselves from Islam.

Reasons immigrant parents prefer a more academic emphasis in the preschool curriculum include:

1. Pedagogical backgrounds. The schools many immigrant parents attended when they were young were more authoritarian and less constructivist 
than their child's preschool. A more academic, more structured (consigne) approach is therefore what many immigrant parents know and expect when they arrive in their new country. This was particularly the case for Turkish immigrant parents in France, whose country of origin shares with their host country Republican values and pedagogical approaches. In contrast, newly arrived Turkish immigrant parents in Germany found the German kindergarten's play-based, multicultural curriculum to be odd and ill-suited to their needs and preferences for their children (Kurban, 2010).

2. Match with their ideological beliefs. Beliefs about preschool pedagogy are tied to more general beliefs about learning, knowledge, and authority. This is true for both more conservative and more liberal beliefs. It is therefore to be expected that immigrants who are members of socially and morally conservative communities will have views on pedagogy and curriculum that are more conservative and that reflect a view of knowledge as something that is transmitted rather than socially constructed, of the asymmetry of adult-child relationships, and of the appropriateness of children showing deference to teachers and other authorities. These values are, of course, not limited to immigrant communities. They are characteristic of education programs in most Catholic, evangelical Christian, orthodox Jewish, and Koranic schools.

3. Pragmatism. Immigrant parents tend to be pragmatic and strategic in the way they think about their children's early education. Rather than having fixed, rigid ideas about what should happen in their children's preschools, immigrant parents make calculations (correct or incorrect) about what their child needs now, the world he/she will encounter in the near and more distant future, and the kind of person they want to see their child become. This parental calculation includes a consideration of both their hopes and their fears, and reflects their assessment of the local context in which they live. Many immigrant parents want the preschool to provide more of an emphasis on academics or on host-language acquisition, not based on a theory of learning but instead on a pragmatic concern about how their child will do in primary school and the consequences of their child doing poorly.

Immigrant parents in Europe and the US tend to think pragmatically about their children's academic readiness for primary school, thinking that leads them to wish for the school to do all it can to help their children "catch-up" with their non-immigrant peers. Immigrant parents see their children as starting out behind and they see it as the school's responsibility to help close this gap. Parents see the gap as resulting not just from their child's lack of fluency in the national language when he or she starts preschool but also from their own lack of cultural capital. This leads them to want the preschool to compensate for what they can't do for their children, such as preparing them to speak, read, and write in a new language. Feeling that they can do a better job on social and moral education than they can on language and on academic preparation, immigrant parents look to the school 
to do what they can't. As an immigrant parent in Germany said, "We can send our children to a play group, but that's not why we send them here." Susanna Mantovani speculates that one reason immigrant parents in Italy are unlike Italian parents in giving higher priority to academic over social skills in the preschool curriculum is that most Italian children are single children, whereas immigrant parents, who tend to have more than one child, are more confident about their children's social skills, and more worried about language and academics.

Given that many immigrant parents have more conservative views on the curriculum that their children's preschool teachers, curricular disagreements are inevitable. This issue played out dramatically at one of our US research sites, a Head Start program in New York City that originally served a mostly African-American community and now serves a mostly Hispanic, new immigrant community. The director and half of the teachers are African-American, the other staff members are from Mexico and Central America. Here, as in many other sites in the U.S. where we conducted research, parents expressed appreciation for the quality of the education and care their children were receiving but also some dissatisfaction with aspects of the curriculum. In a discussion conducted in Spanish, parents expressed support for the program's emphasis on social and emotional development and an understanding of the program's philosophy that children learn best through play. But many of the parents also told us that they wanted more academics and less play:

Interviewer: Is there anything you would like to see changed here?

Mother 1: "The most important thing is get them ready for kindergarten."

Mother 2: The teachers are very nice and the playtime is good. But I wish they would work more on their letters.

Mother 3: "They should know how to write their names and they should know their numbers."

Father 1: $\quad$ Maybe just a little more time on learning their letters and numbers.

Mother 1: $\quad$ So they'll be ready for kindergarten.

When we concluded the discussion by asking these parents if there was anything they wanted us to communicate to their children's teachers, one mother said: "Just ask them, 'Would it kill you to teach my child to write her name before she enters kindergarten?"'

We did ask this question in a subsequent meaning with the teachers, whose answer was that to give in to such pressures from parents would mean to go against their professional beliefs and knowledge. In an interview we conducted in Spanish with five of the teachers, most of whom are themselves immigrants from the Dominican Republic, Puerto Rico, and Mexico, they explained their core beliefs:

Ms. Gomez: Some parents think that we do not teach the ABC's.

Ms. Diaz: We do teach it, but not formally like "Sit here, this is an A, this is a B, but rather through play.

Mr. Alomar: Many parents bring their children to us with the hope that they will learn to read and write here.

Ms. Gomez: With the same methods that they learned as children. 
Ms. Diaz: But we use different methods, because times have changed.

Ms. Gomez: For example, back in our country, when they go to school for the first time, most children did not go Head Start; they just went to kindergarten in a place like Santo Domingo [the Dominican Republic], where the teacher would seat you at a desk, and it's like, "Let's go. Write these letters." They would even hold your hand, you know, to show you how to write the letters. That was really something. The parents, like us, who come from another country, think that when they come here...

Ms. Diaz: $\quad$...that it should be that way.

Ms. Gomez: And they don't understand that through playing they are learning.

These teachers suggest that parents' perspectives reflect antiquated methods from the old county, which they describe as simplistic, mechanistic, and prescriptive. A teacher states that in the old system teachers would guide the child's hand to show her how to write and they suggest that nowadays pedagogy has developed more sophisticated ways of working with children.

We returned the next year to share our preliminary findings with the school's director, an African-American educator with a Master Degree in Early Childhood Education from the Bank Street College of Education (one of the centers in the US of contructivism):

Tobin: $\quad$ Many of the immigrant parents here told us that they want more direct instruction and academic emphasis. Are you aware of this?

Director: Yes, of course. We hear this all the time.

Tobin: What would you say to the idea that you should change your approach to be closer to what the parents want?

Director: "We shall not be moved."

The director's invoking here of the key line in the anthem of the American civil rights movement is pointed. This citation of the African American struggle for civil rights (and specifically of Rosa Parks' refusal to move to the back of the bus) suggests that it would, in a metaphorical sense, kill her and her staff of teachers to teach the $A B C$ s because it would force them to go against their understanding of themselves as professionals and to betray their core professional beliefs.

Given that many immigrant parents have more conservative views on the curriculum that their children's preschool teachers, curricular disagreements such as the one above are inevitable. A key finding of this study is that preschool teachers who work with immigrant children and their families often find themselves caught between two core professional values: their beliefs in constructivist, progressive, pedagogy on one hand, and their belief in being culturally responsive and sensitive on the other. (This tension is much less strongly experienced by teachers in France, where being culturally responsive is not a professional expectation of teachers, than it is in England, where such responsiveness has been written into law). 
Most progressive educators (again, except in the case of France) are more than willing to bring the culture of the home into the classroom in the form of songs, stories, artwork, holidays, and food. But teachers are much less willing to adjust or modify their teaching in response to parents' cultural beliefs involving gender issues or the curriculum. We found many examples in our focus-group discussions of teacher's willingness to make accommodation for dietary concerns of immigrant parents, and (except for France) to tolerate or even celebrate cultural diversity in dress and in holidays. For example, in response to our questions about their willingness to change their practice to accommodate immigrant parents' wishes, teachers in Germany, Italy, and England most often cited how they have made allowances for children who for religious reasons do not eat pork. But, as we can see in the "Would it kill you to teach my child to write her name"/"We shall not be moved" example, when discussion moves from food and clothing to questions about the curriculum, teachers and directors become much more resistant to making accommodations for parents' wishes.

Christa Priessing suggests that one reason many of the German teachers in this study are uncomfortable about the idea of entering into dialogue with immigrant parents is that:

Teachers fear they would have to change their work to make it more aimed at preparing children for the formal school system. Teachers told us, "If this happens, we would lose our autonomy based on our professional beliefs and backgrounds. These parents ask us teachers to have the children bring home more produced projects, handicrafts, etc, which we won't do." These teachers fear engaging with parents who have more conservative expectations than they do, and fear coming under pressure to defend their professional work (Priessing, 2009).

There are several reasons for this resistance. One is that teachers believe that their curricular and pedagogical knowledge is what distinguishes them from parents and that the power to decide what and how to teach is at the core of their professionalism. Most ECEC practitioners think of their curriculum beliefs as based on research, logic, and their training in best practices, and not as being culturally constructed, contingent, or habitual. Most teachers do not conceive of parents' curricular wishes as being cultural beliefs that, like beliefs about food, religion, and dress, should be respected or negotiated but instead view parents' curricular preferences as forms of ignorance, to be corrected. The cost of early childhood educators seeing their beliefs about practice as professional codes that must be followed is that they position parents' wishes as deficits, as misunderstandings needing correcting rather than as ideological differences needing negotiating. In many cases the gaps between teachers' and parents' views are not huge, but they are often perceived by teachers as being insurmountable. (France is an exception here, in that there is little or no expectation in the French ECEC system of teachers being responsive to parents).

Reasons for teachers' hesitation if not outright refusal to engage in discussions and negotiations over the curriculum with immigrant (and other) parents include: a defensiveness growing out of their feeling of relative powerlessness--though 
more powerful than immigrant parents, preschool teachers in many settings feel vulnerable and disrespected; a fear of losing their hard-won professionalism (to accede to parents' curricular requests might make them appear to other teachers, directors, and evaluators to be back-sliding and failing to perform the progressive positions in which they were trained; fear that if they agree to enter into dialogue with parents about their practices that this will "open the floodgates" and they will have to compromise core beliefs; the fear of being outnumbered in meetings with parents; the fear that immigrant parents will have exotic and unrealistic requests, demands, and expectations; and the fear of saying something politically incorrect and offensive and then being attacked.

Michel Vandenbroeck eloquently summarizes the dilemma that confronts not only progressive preschool teachers and directors, but the early childhood professoriate and policy community as well:

\begin{abstract}
Some ethnic minority parents protest against what they view as a non-academic direction of multicultural curricula and ask for a more 'traditional' magister, directing the learning and disciplining the children when necessary. Some parents reject the presence of bilingual assistants or of the home language of the child in the centre. . . As progressive academics or practitioners, how can we not take into account the perspective of parents who wish to 'conform' to standards of academic achievement (or to achieve this cultural capital as Bourdieu could have said), rather than to discuss holistic education? But on the other hand, how can we, if we have consecrated a major part of our lives to child centeredness? As a critical pedagogue I may argue that this parental question of conformity with the dominant norms and values is to be considered as "internalised oppression" (Freire, 1970). But then again, wasn't it also Freire who said "Dialogue cannot exist without humility. [...] How can I dialogue if I always project ignorance onto others and never perceive my own?" (1970, 78). (Vandenbroeck, p. 167, 2009)
\end{abstract}

\title{
Culture, Class, and Ideology
}

Many of the positions we have presented here as characteristic beliefs of immigrant parents are beliefs that were also put forward in our focus groups by non-immigrants parents. This is especially true for immigrant and non-immigrant parents of similar class backgrounds. For example, in the US focus groups we found that the desire for more explicit emphasis on academics that was expressed by many new immigrant parents was shared by many working-class white and African-American parents. This suggests the need to attend to the intersectionality of immigration status, culture, and class. Some differences between immigrant parents and teachers that we have ascribed to culture could be ascribed to class. And just as we should be careful not to use the category of culture to mask class, we need to avoid using the concepts of culture and class to mask ideological disagreements that transcend these categories. Beliefs about the means and ends of early childhood education cross cultural and class lines, as in the case of some socially conservative upper- and middle-class parents in our study who share with many of the working class immigrant parents a preference for an approach to education that emphasizes respect for teachers and a transmission model of learning. An irony is that those members of society who tend to be the most 
anti-immigrant often tend to share with many immigrants socially conservative perspectives on education.

This having been said, there are also concerns that are particular to immigrant parents as, for example, concerns about first language retention, experiences of anti-immigrant prejudice, and worries and ambivalence about cultural identity and citizenship issues both for themselves and their children.

\section{Conclusion}

In preschools as in other social settings and domains, there is a tendency to project onto immigrants problems of the larger society. We found many examples of such projection in our interviews with teachers and non-immigrant parents. For example, many teachers complained of the pressure they get from immigrant parents to give more emphasis to academics, but making this complaint about immigrants masks the reality that this pressure comes as well from many nonimmigrant parents. Teachers in our study complained that it is difficult for them to communicate with immigrant parents, a statement that implies that it is easy for them to talk to non-immigrant parents, when the literature on parentteacher relationships suggests that this is not the case. Projecting the problem of communicating with parents onto the immigrant allows teachers to avoid dealing with the fact that they struggle to communicate with parents in general.

Engaging with the difficult questions raised by the challenge of working with immigrant children and their families can have the benefit of leading to an opening up of dialogue on issues that impact all children and families. The presence of immigrants can catalyze a rethinking and reworking of educational practices and policies, not only practices and policies for educating children of recent immigrants, but practices and policies for all children. The immigrant, as a stranger, presents both a threat and an opportunity for the host society. As Michel Vandenbroeck writes:

It is the Other who urges us to make our decisions transparent and therefore disputable and who forces us to acknowledge that these disputable decisions can never be merely the results of protocols for the sake of protocols or based on a higher moral order. This requires various ways in which decisions can be documented, to make them transparent, and therefore disputable. What it also requires is the time and space to allow ourselves to ask the difficult questions about how the dispute compels us to rethink our conceptions of what 'good practice' may be, over and over again. Obviously, this makes the work of professionals in early childhood quite demanding, both for researchers and practitioners in the field, as it questions too many taken for granted assumptions (p. 168, 2009). 


\section{References}

Adair, J. \& Tobin, J. (2007). Listening to the Voice of Immigrant Parents. In C. Genishi, L. Goodwin (eds.) Diversities in Early Childhood Education: Rethinking and Doing, Routledge Falmer.

Bove, C., Mantovani, S. (2006). Alle soglie della consapevolezza [On the threshold of awareness]. In G. Favaro (A cura di) Nello stesso nido. Milano: Franco Angeli, pp. 13-34.

Brougère, G., Guénif-Souilamas, N. \& Rayna, S. (2008). Ecole maternelle (preschool) in France: A cross-cultural perspective. European Early Childhood Education Research Journal, 16(3), 371-384.

Delpit, L. (1996). Other people's children: Cultural conflict in the classroom. New York: The New Press.

Guénif-Souilamas, N. (2008). “Regards croisés sur l'accueil des enfants de migrants en maternelle", with Gilles Brougère \& Sylvie Rayna, VEI Diversité, Juin, no. 156, CNDP.

Pascal, C. \& Bertram, T. (2007). Children Crossing Borders: Enhancing the Inclusion of Children in Pre-school Settings, Children in Europe, 13, 13-14.

Priessing, C. (2009). Unpublished interview.

Shutz, A. (1944). The Stranger, The American Journal of Sociology, 49, 499-507.

Tobin, J. (2000). Good Guys Don't Wear Hats: Children's Talk about the Media. Teachers College Press.

Tobin, J., Wu, D., \& Davidson, D. (1989). Preschool in Three Cultures: Japan, China, and the United States, Yale University Press.

Tobin, J., Hsueh, Y., \& Karasawa, M. (2009) Preschools in Three Cultures Revisited: China, Japan, and the United States. University of Chicago Press.

Valdes, G. (1996). Con Respeto: Bridging the Distances Between Culturally Diverse Families and Schools: An Ethnographic Portrait. New York: Teachers College Press.

Vandenbroeck, M. (2009). Let Us Disagree. European Early Childhood Education Research Journal, 17(2), 165-170.

Vandenbroeck, M., Roets G., \& A. Snoeck, (2009). Immigrant mothers crossing borders: Nomadic identities and multiple belongings in early childhood education. European Early Childhood Education Research Journal, 17(2), 203-216.

\section{Contact Information}

Prof. Joseph Tobin and Dr. Frikriye Kurban

School of Social Transformation

Arizona State University

P. O. Box 874902

Tempe, AZ 85287-4902

U.S.A.

joseph.tobin@asu.edu 